\title{
An Empirical Study of High-frequency Trading Risk Regulation -Based on the CSI 300 Index Data
}

\author{
Song GE \\ Department of Economics and Management \\ Xi'an University of Posts and Telecommunications \\ Xi'an 710121, China
}

\author{
JianFeng GUO \\ Department of Economics and Management \\ Xi'an University of Posts and Telecommunications \\ Xi'an 710121, China
}

\begin{abstract}
In recent years, high-frequency trading as a frontier and hot issues of modern finance, has attended much attention in china. At 11:05, August 16, 2013, Shanghai index moved up sharply, with the grail increasing more than $5 \%$ in one minute. The highest index was reported 2198.85. Media call this event as "Everbright oolong index event". Oolong index is a consequence of high-frequency trading playing an important role in the market. In the study, based on CSI 300 index high frequency trading data from May to December, we employ VPIN model and optimize calculation. We use MATLAB software to scroll calculate daily VPIN value and aggregate it, to measure the risk of stock index futures market. Through empirical research, we concluded that VPIN index has a role in early warning, and it can be used as risk control indicators.
\end{abstract}

Keywords- High-Frequency Trading; Risk Regulation; Everbright Oolong Index

\section{INTRODUCTION}

Market microstructure trading ideas is to extract information from observed quote data, and according to the extracted information initiate the trading to profit. Asymmetric market information can lead to adverse selection, that's because informed traders profit form uninformed traders.

High-frequency trading swept Wall Street like a storm, with nearly $2 \%$ of high frequency trading firms accounted for $70 \%$ of stock market trading volume and $50 \%$ of futures trading volume. These high frequency trading firms play a role of market makers, providing mobility for the market.

Instruction stream toxicity will bring a huge market risk. Tradition measurement of instruction stream toxicity is PIN value, that is, deduce the probability of informed trading from quote data sequence. Based on PIN, Easley (2011) proposed a new method VPIN, to directly estimate the instruction stream toxicity in high-frequency trading. Liu Wenwen and Zhang Hejin (2013) once attempted to measure the instruction stream toxicity in china's stock index futures market. The empirical results showed that, VPIN not only can detect the instruction stream toxicity when CSI 300 index crash, but also well detect it when the index surge.
At 11:05, August 16, 2013, Shanghai index moved up sharply, from 2074 to 2198.85 , with the grail increasing more than $5 \%$ in one minute. It was found afterwards that, this was an oolong because of problems of Everbright securities proprietary trading strategy system. When closing quotation at that day, shanghai index fell by $0.65 \%$ again.

The stock market of our country these years has never seen such a big scene. Such a rare oolong in the stock market has brought the issues of mechanism risk control and crossmarket regulatory vacuum behind "quantitative investment" and "hedging".

In this study, we reference the advanced research idea and method of flash crash, employ the new VPIN indicator to detect instruction stream toxicity, providing risk regulation means for regulators, so that greatly reduce the probability of the malignant event like "Everbright oolong index event".

\section{VPIN MODEL AND ITS CALCULATION}

\section{A. VPIN Model and Parameter Estimation}

In Easley's (2012) article, he proposed an analysis estimation of direct toxicity measurement in high-frequency market, without the median estimation of unobservable parameters. They improved the algorithm, trying to match transaction amount of time with new message arrival speed in the market. The volume-based algorithm was called as "VPIN", providing a simple method for measuring instruction stream toxicity in the high-frequency trading environment. First, we begin with the discussion on the role of information and time in high-frequency trading.

1) The Essence of Information and Time

In the standard continuous trading model, information is often seen as data. In the stock market, we naturally consider information about future events, such as company's prospects or future market of its products. In an efficient market, the value of assets should be closer to its full value of information, and informed traders utilize this information to profit through transaction. Because the market maker can guide the market going long or going short, asset value changes will affect their rate of return, and they attempts to infer the new message hidden from the trading mode.

In the high-frequency trading, although they change things in interesting ways within the operable scope, market makers are faced with the same basic problems. Maybe the information is associated with the asset base, but it may 
reflect the essence of transaction in the market, or is the specific the related factors of liquidity needs in a specific time interval. For example, in the futures contract, the information that causes increasing demand for the contract hedging will have common effect on futures price. Such generalized information means information events will occur frequently in one day, and have different importance for the future price trend. In spite of this, they still suggest the nature and time of the transaction.

\section{2) Trading Volume Basket}

In order to realize the independent sampling of transactions volume, we put a group of continuous trading into the transactions basket for exogenous definition $V$. One transactions volume basket is a collection of the total trading volume $V$ of a transaction. If the last transaction in transaction basket is larger than the required transaction volume, then the exceeded volume will be transferred to next trading volume basket. Remark the serial number of equalamount transaction as $£=1, \ldots, n$. Trading volume basket sampling allow us to divide the entire transaction into transaction phase according to the comparable information contents. Trade imbalance is providing meaningful economic impact on mobility.

\section{3) Trading Volume Time}

VPIN indicator will be updated once a trading volume basket is generated. This way, when 51 baskets are full, we discard the first basket and calculate new VPIN based on 251 baskets. There are two reasons that we update the VPIN according to trading volume time: firstly, we hope that the update speed of VPIN can match the speed of information reaching the market. We take transaction volume as arrived information representative accomplish this goal. Secondly, we hope every update is based on a considerable amount of information. Transaction volume can divide the entire trading period with very unbalanced and low participation, and in such a segment of small trading volume, it seems unnecessarily to generate new information.

\section{B. VPIN Calculation}

Based on probability of informed trading (PIN), Easley (2011) propose a new method-VPIN to directly estimate the instruction stream toxicity in high-frequency trading. VPIN indicator is shown in Formula (1):

$$
V P I N \approx \frac{\sum_{\tau=1}^{n}\left|V_{\tau}^{S}-V_{\tau}^{B}\right|}{n V}
$$

To estimate VPIN value, we need the trading volume V; $\mathrm{n}$ is the number of basket; ${ }_{\tau}^{S}$ (sales volume of each basket) and $V_{\tau}^{B}$ (buy volume of each basket) take a fixed time interval, to estimate the amount within this period of time by trading volume probability distribution. In this article, we optimize the VPIN algorithm, with fixed trading volume basket size, and employ the trading volume individually distinguish dealings method to aggregate the volume of trading volume basket $(\mathrm{V}) . \mathrm{V}$ is determined, while basket number $\mathrm{n}$ is uncertain every day, produced with rolling. Results of this study is robust in a wide range selection of values $\mathrm{v}$ and $\mathrm{n}$, detailed discussion shown in Chapter III

\section{EMPIRICAL RESEARCH BASED ON EVERBRIGHT BANK OOLONG INDEX EVENT}

In Chapter II, we have examined the robustness of the VPIN index calculation, and now we will do empirical research on CSI 300 index futures market.

\section{A. Sample Selection and Empirical Research}

The sample in this chapter is CSI 300 index futures market main contract transaction data From May $2^{\text {nd }}, 2013$ to December $31^{\text {st }}, 2013$.

In the empirical research, assume the amount of trading volume basket $V$ is $60 \%$ of average daily trading volume during the sample period. Based on the model, employ MATLAB software to scroll calculate daily VPIN value and aggregate it. Focus on Extraction of VPIN performance the day of Everbright oolong index event.

\section{B. Empirical Results}

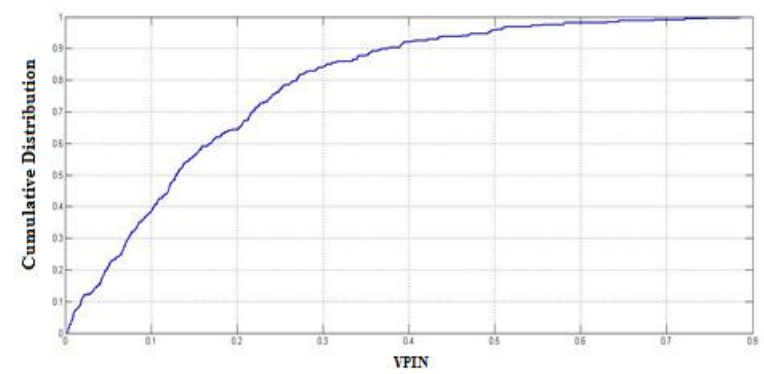

Figure 1. VPIN Cumulative Distribution

From the cumulative distribution curve of VPIN in Figure 1, we can see the market risk more intuitively. In the graph, nearly $90 \%$ of VPIN value is below 0.4 . It indicates that only in very few cases will VPIN value be higher than 0.4 . We can regard 0.4 as a high-risky critical value to compare.

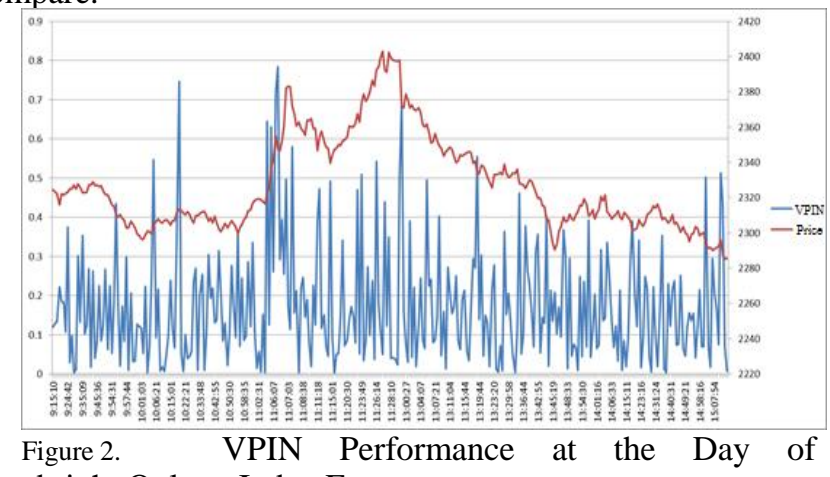

Everbright Oolong Index Event

Figure 2 shows the evolution over time (red line) and VPIN value (blue value) at the day of Everbright oolong index event. Since opening quotation, VPIN value has shown the trend of increase, and the value more than 0.4 emerged within 10 minutes. At this time the price did not substantially change, and there is no upward trend. It indicates at least 1 
hour before oolong index event happened, VPIN indicator has revealed that the market has a high level of risk. However, at two minutes before oolong index event, VPIN value reached the highest value 0.78 (approach 1), very directly revealing the superb high level risk. Thus we can see that it plays a role in early warning; while in the rest of the day market can also reflect the early warning effect. When the oolong index event happened in the morning, then make going short for hedging. Although the stock price fell all the way, VPIN still Keep in a higher position in the rest of the day. Even if it is at the lowest price in the end, it still showed the value higher than 0.5 . It shows that market is still at high risk, so the market participants should be circumspect.

\section{VPIN ROBUSTNESS TEST}

VPIN volatility index test includes various parameter problems. In this Chapter, by selection process of different trading volume basket, we demonstrate the robustness of VPIN measurement.

How to select the amount of trading volume basket is an important factor in VPIN robustness test. For the algorithm used in the past, because VPIN contained trade imbalances and trade intensity, gathering a certain time interval can reduce variables noise and readjust. By observing the VPIN value performance of trading volume with different time intervals, we can test the robustness. In Easley, Lopez and O' Hara' papers (2012), using the data on flash crash day, by 1 minute, 10 seconds, Lee-Ready algorithm respectively aggregate interval to distinguish between trading volume and aggregate different trading volume basket. These three methods all can point out VPIN has a high level of risk at least 2 hours before crash.

In this article, we employ individually trading distinguishing trading volume to aggregate trading volume basket, and scroll calculate VPIN value with trading volume basket. However, the size of trading volume basket $(V)$ would affect VPIN calculation. Because the bigger is $V$, the smaller basket number $n$ will be. If the $V$ is set too small, rolling calculation for so many times, although it is more accurate, the calculation amount will be also increasing. For one thing, we should ensure the accuracy of VPIN value calculation; for another, we should control the calculation amount, so that avoid redundant futilities, so selection of trading volume basket is very important. Take the VPIN value on August 16, 2013 (oolong index event day) for example:

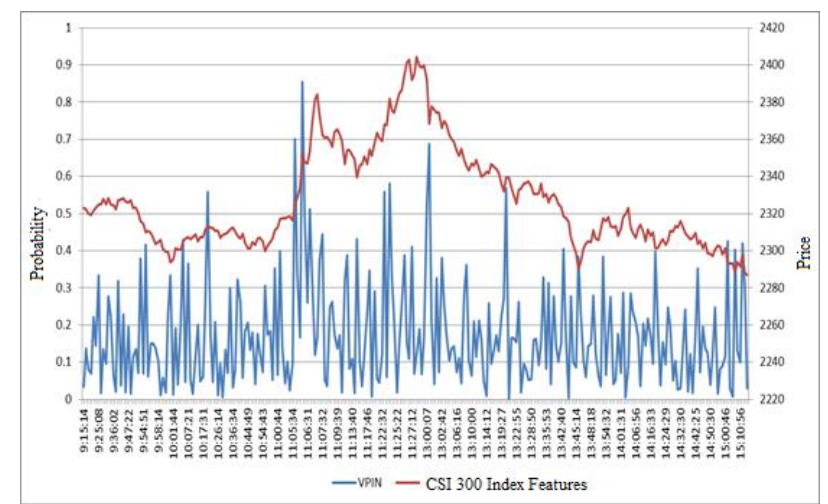

Figure 3. Amount of Trading Volume Basket is 50\% of Average Daily Trading Volume

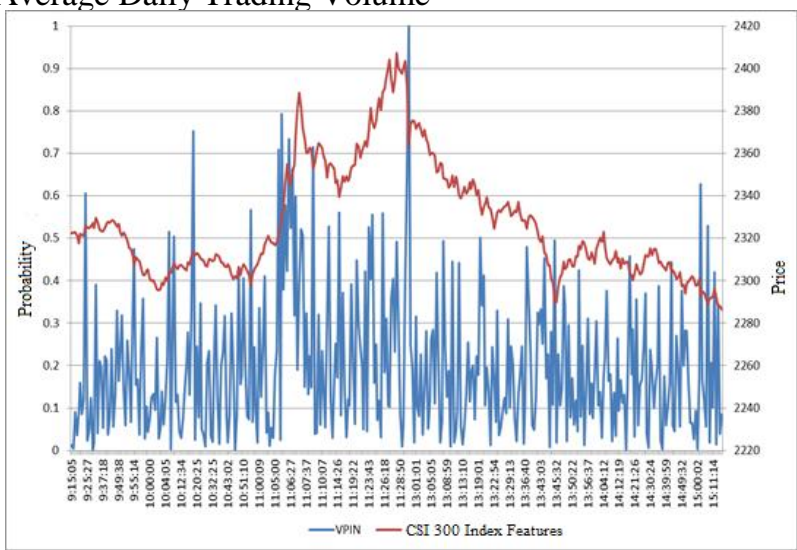

Figure 4. Amount of Trading Volume Basket is $70 \%$ of Average Daily Trading Volume

These two points system both pointed out VPIN has a high level of risk 1 hour before oolong index event happened. Correlation level between fiftieth average daily trading volume during sample period and seventieth average daily trading volume during sample period with VPIN value produced qualitative similar results. In these selection of different trading volume basket, VPIN value all have very obvious signal at least 1 hour before oolong index event happened. The range of variation is increased significantly, and although prices fell sharply in the rest of the day, VPIN still kept in a higher position, suggesting it has warning effect and good robustness.

\section{CONCLUSIONS}

In this article, we employ a new method VPIN, based on Everbright oolong index event, to estimate the risk level of China's high-frequency trading (here mainly for CSI 300 index futures market). Through empirical research, we concluded that VPIN index has a role in early warning. Regulators can refer to VPIN index to pursue risk regulation, and avoid market turmoil.

\section{ACKNOWLEDGEMENT}

Funding Project: National Ministry of Industry and Infor mation Technology Soft Science Research Program Funded Projects (2012-R-08-2) 


\section{REFERENCES}

[1] CME Group. Statement on the Joint CFTC/SEC Report Regarding the Events of May 6, October 1, 2010.

[2] Brunnermeier M. and Pedersen L. Market Liquidity and Funding Liquidity [J]. Review of Financial Studies, 2009, 22 (6): 2201-2238.

[3] CFTC. 2010. Proposed Rules, Federal Register, 75 (112) (June 11): 33198-33202. Chaboud, A., E. Hjalmarsson, C. Vega and B. Chiquoine. 2009. Rise of the Machines: Algorithmic Trading in the Foreign Exchange Market, FRB International Finance Discussion Paper No. 980.

[4] Hendershott T, Jones C. and Menkveld A. Does Algorithmic Trading Improve Liquidity? [J] .Journal of Finance, 2011, 66 (1): 1-33.

[5] Glosten L. R. and Milgrom P. Bid, Ask and Transaction Prices in a Specialist Market with Heterogeneously Informed Traders [J]. Journal of Financial Economics, 1985, 14: 71-100.

[6] Easley D. and O'Hara M. Price, Trade Size and Information in Securities Markets [J] .Journal of Financial Economics, 1987, 19: 6990
[7] Easley D. and O'Hara M. Time and the process of security price adjustment [J] .Journal of Finance, 1992, 47: 576-605.

[8] Deuskar P. and Johnson T. Market Liquidity and Flow-driven Risk [J] .Review of Financial Studies, 2011, 24 (3): 721-753.

[9] Easley D, Kiefer N, O'Hara M. and Paperman J. Liquidity, Information, and Infrequently Traded Stocks [J] .Journal of Finance, 1996, 51:1405-1436.

[10] Easley D, Engle R F, O'Hara M and L. Wu. Time-Varying Arrival Rates of Informed and Uninformed Traders [J].Journal of Financial Econometrics, 2008, 6(2):171-207.

[11] Easley D., M. López de Prado and M. O'Hara. The Microstructure of the Flash Crash. The Journal of Portfolio Management [J].2011a,

[12] Easley D, López de Prado and O'Hara M. The Exchange of Flow Toxicity [J]. The Journal of Trading, 2011b, 6(2):8-13.

[13] Easley D, López de Prado and O'Hara M. Flow Toxicity and Liquidity in a High Frequency World [J]. Review of Financial Studies, 2012, 5: 1457-1493. 